Res., Soc. Dev. 2019; 8(1):e181504

ISSN 2525-3409 | DOI: http://dx.doi.org/10.33448/rsd-v8i1.504

\title{
Estudo de proteção contra corrosão em armaduras de aço da construção civil
}

\section{Corrosion protection study in construction steel armor}

Estudio de protección contra la corrosión en armaduras de acero de la construcción

\section{Pedro Emílio Amador Salomão}

Universidade Presidente Antônio Carlos, Brasil

E-mail: pedroemilioamador@yahoo.com.br

\author{
Alberto Suski \\ Universidade Presidente Antônio Carlos, Brasil \\ E-mail: albertosuski@emexdobrasil.com.br \\ Willian Farias Pinheiro \\ Universidade Presidente Antônio Carlos, Brasil \\ E-mail: willian.pinheiro@copanor.com.br
}

Alcilene Lopes de Amorim Andrade

Universidade Presidente Antônio Carlos, Brasil

E-mail: alcileneaguia@ hotmail.com

Recebido: 08/07/2018 - Aceito: 16/08/2018

\section{Resumo}

Neste trabalho é estudada uma alternativa a proteção contra corrosão nas armações metálicas utilizadas na construção civil. Estruturas metálicas expostas ao intemperismo podem contribuir para a degradação de toda a estrutura de concreto de um prédio, processo este denominado corrosão de concreto, que gera prejuízos enormes as construtoras e compromete por vezes até toda a estrutura de um prédio, sendo mostrado nesse trabalho um método de proteção das estruturas metálicas da construção civil. Realizando uma breve revisão da literatura e experimentos, este trabalho mostra a eficiência da proteção de barras de aço envolvidas com uma fita de magnésio, tendo a confirmação da eficiência por metalografia que mostram a superfície do metal, e da presença de espécies química, por difração de raio $\mathrm{x}$ (DRX). É possível verificar que os resultados são promissores, fornecendo para a engenharia um caminho que até hoje é pouco pesquisado, envolvendo um leque de áreas que vão desde as grandes construções, até as casas mais simples, que poderão ter uma vida útil mais longa e com menos gastos de manutenção.

Palavra chave : Estruturas Metálicas. Corrosão. Circuito com placa de magnésio. 


\section{Resumen}

En este trabajo se estudia una alternativa a la protección contra la corrosión en los armazones metálicos utilizados en la construcción civil. Las estructuras metálicas expuestas al intemperismo pueden contribuir a la degradación de toda la estructura de hormigón de un edificio, proceso que se denomina corrosión de hormigón, que genera pérdidas enormes a las constructoras y compromete a veces hasta toda la estructura de un edificio, siendo mostrado en ese trabajo un trabajo método de protección de las estructuras metálicas de la construcción civil. En este trabajo se muestra la eficiencia de la protección de barras de acero envueltas con una cinta de magnesio, teniendo la confirmación de la eficiencia por metalografía que muestran la superficie del metal, y de la presencia de especies químicas, por difracción de radiografía (DRX). Es posible comprobar que los resultados son prometedores, proporcionando a la ingeniería un camino que hasta hoy es poco investigado, involucrando un abanico de áreas que van desde las grandes construcciones, hasta las casas más simples, que podrán tener una vida útil más larga y con menos gastos de mantenimiento.

Palabra clave: Estructuras metálicas. La corrosión. Circuito con placa de magnesio. 


\begin{abstract}
In this work an alternative is studied the protection against corrosion in the metal frames used in the construction. Metallic structures exposed to weathering can contribute to the degradation of the entire concrete structure of a building, a process called concrete corrosion, which generates huge damage to construction companies and sometimes compromises to the entire structure of A building, being shown in this work a method of protection of the metallic structures of the construction. Conducting a brief review of the literature and experiments, this work shows the efficiency of the protection of steel bars involved with a magnesium tape, having confirmation of efficiency by metallography that show the surface of the metal, and the presence of Chemical species by X-ray diffraction (DRX). It is possible to verify that the results are promising, providing for engineering a path that is not currently researched, involving a range of areas ranging from the large buildings, to the simplest houses, that can have a longer lifespan and with Less maintenance expenses.
\end{abstract}

Keyword (s): Metal Structures. Corrosion. Circuit with magnesium plate.

\title{
1. Introdução
}

A corrosão é um dos grandes problemas enfrentados por qualquer área industrial e comercial que trabalha com estrutura de aço. Armaduras e estruturas metálicas estão sendo estudadas e analisadas de acordo com sua resistência a corrosão. Nos últimos anos, vem sido estudado com mais frequência uma vez que foram levantados estatísticas apontando o alto custo de manutenção em relação a corrosão, já que isso é uma preocupação mundial.

Neste trabalho são mostradas as estruturas metálicas expostas às ações de intempéries, que são os principais agentes causadores mais visíveis à corrosão.

O estudo da corrosão vem para suprir a necessidade de se conseguir manter as estruturas mais intactas, sem o comprometimento da corrosão, a patologia da corrosão nas estruturas com concreto armado, tem sua origem quando há uma interface entre o concreto armado e a armadura metálica.

A técnica de proteção contra a corrosão consiste em fazer um circuito elétrico, interligando as estruturas metálicas entre si com uma fita de magnésio, criando assim um circuito de troca de elétrons, onde a placa de magnésio doará elétrons para a estrutura metálica preservando assim suas características, fazendo com que a placa de magnésio seja 
sacrificada contribuindo para a redução da corrosão. Consequentemente obtém-se uma proteção para as estruturas metálicas, podendo oferecer a manutenção a cada período da placa fazendo com que o circuito fique em funcionamento periodicamente.

Com todas essas descrições, este trabalho tem por objetivo a obtenção de um método eficiente para proteger armaduras metálicas utilizadas em construção civil com intuito de aumentar a sua vida útil, na qual é feita a proteção utilizando um metal de sacrifício.

\section{Revisão de Literatura}

Existem vários modelos para análise da vida útil das armaduras; e um modelo clássico proposto por Tuutti ( 1982 ), uns dos mais divulgados nos meios técnicos, sugere que a vida útil das armaduras são divididas em duas fases: a iniciação e a propagação. SALOMÃO, P. E. A. et al. (2018) descreva a elaboração de vigas de concreto, na qual para conferir estabilidade, usa-se uma estrutura metálica, como pode ser ilustrado na Figura 1, onde temos a estrutura metálica envolvida pelo concreto.

Figura 1: Elaboração de uma viga, tendo a estrutura metálica envolvida por concreto.

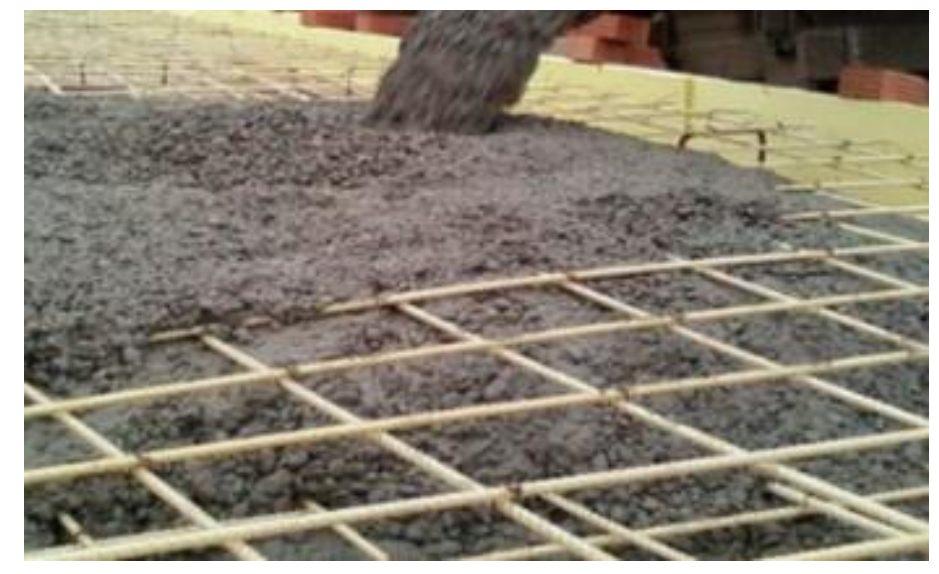

(Fonte: Autoria própria)

Como ilustrado na Figura 1, as estruturas metálicas ficam em contato com o concreto, que de acordo com sua elaboração pode ficar mais ou menos poroso, o que no longo prazo acaba ocasionar em severos problemas provenientes da corrosão.

O período de iniciação corresponde ao tempo desde a execução da estrutura até a ação do agente agressivo em atravessar o cobrimento do concreto, alcançar a armadura e iniciar o processo de corrosão. 
O segundo período, denominado da propagação corresponde ao desenvolvimento do processo corrosivo até níveis inaceitáveis de deterioração (BROOMFIELD, J. P. 2003).

Segundo a ABNT NBR 6118:2014, durabilidade consiste na capacidade de a estrutura resistir às influencias ambientais, previstas e definidas em conjunto pelo autor do projeto estrutural e pelo contratante, no início dos trabalhos de elaboração do projeto. Portanto, a durabilidade não é uma propriedade inerente ou intrínseca à estrutura, armadura ou ao concreto. Uma mesma estrutura pode ter diferente comportamentos, ou seja, diferentes funções de durabilidade no tempo, segundo suas diversas partes, até dependente da forma de utilizá-la. (GONZALEZ, J. A. et al. 1995).

Um material atinge o fim de sua vida útil quando suas propriedades, sob determinadas condições de uso, tiverem se deteriorado de tal forma que a continuação de sua utilização se torna insegura e antieconômica (ANGST, U. M. 2018)

A necessidade de inovação e solução para um problema do cotidiano na construção civil, que afeta tanto na área social quanto na financeira, a corrosão das armaduras nos concretos, é um problema nas grandes obras públicas e privadas onde se gasta valores consideráveis de recursos, na qual não existe uma solução simples, eficaz e acessível. Visto que uma vez danificada a estrutura os valores de manutenção atinge escala altíssima, já se condenada a estrutura a construção poderá ser condenada, sem contar os transtornos causados (ZHU, Wenjun et al 2017).

Técnicas de proteção de estruturas metálicas mais comuns, são, porém, geram alto custo, impactando o valor final da obra. O método desenvolvido nesse trabalho tem como primeiro pensamento em evitar grandes danos nas estruturas metálicas e armaduras das cidades litorâneas (BOKATI, K. S. et al. 2017).

Quando o metal utilizado na construção civil, fica exposto a umidade presente no ar atmosférico, o mesmo reage com oxigênio e a água, em uma reação na qual ele perde elétrons, se tornando uma espécie oxidada como ilustrado na equação 1. Na Figura 2 pode ser observado e resultado da oxidação em uma viga de concreto com o passar dos anos (SVORONOS, 2017).

$$
2 \mathrm{Fe}_{(\mathrm{s})}+3 / 2 \mathrm{O}_{2(\mathrm{~g})}+3 \mathrm{H}_{2} \mathrm{O}_{(\mathrm{g})} \rightarrow 1 \mathrm{Fe}_{2} \mathrm{O}_{3} \cdot 3 \mathrm{H}_{2} \mathrm{O}_{(\mathrm{s})}
$$


Figura 2: Exemplo de uma viga em um edifício, que sofre oxidação com o passar do tempo, comprometendo a estrutura.

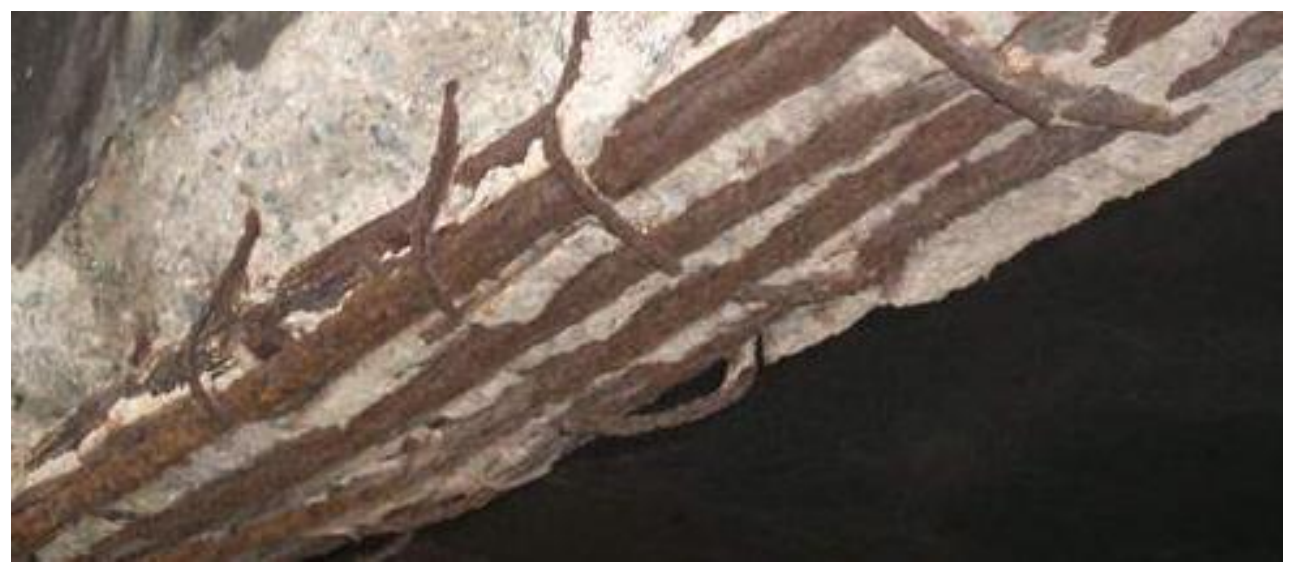

(Fonte: Autoria própria)

Como ilustrado na Figura 2, pode ser visto que quando exposta a umidade, mesmo que de forma lenta e gradual, a estrutura metálica sofre com a oxidação o que compromete toda a sustentação na qual ela realiza.

Partindo do princípio de que toda a estrutura se comporta como um circuito fechado, o metal de sacrifício, incorporado a estrutura, retarda e em alguns casos protege contra a corrosão a estrutura ou armadura metálica. Dessa forma pode-se afirmar que a estrutura será protegida, e de tempos em tempos é preciso trocar apenas a placa de magnésio que foi sacrificada, por outra, preservando assim a estrutura ou armadura metálica se comportando como um estrutura interligada, o metal de sacrifício irá doar elétrons para o metal a ser protegido, evitando o seu desgaste-, (HÁ, J. H. et al. 2017).

Visto as grandes consequências da corrosão em estruturas metálicas, a técnica de proteção das mesmas, recebe uma grande importância, que vai desde uma simples construção no litoral onde a agressividade da corrosão é maior, até em grandes obras. Com esse método de proteção, utilizando um metal de sacrifícios, espera-se que além da proteção da estrutura metálica, ocorra também a redução do custo direto na manutenção, na qual as armaduras e as estruturas de concretos sofrerão menos danos, proporcionando assim um prazo mais longo de vida útil das estruturas (MCCULLOUGH, et al. 2017). 


\section{Metodologia}

Sabe-se que a corrosão inicia logo que a estrutura entra em contato com a umidade e dependendo da região os agentes têm sua potência aumentada, contribuindo para acelerar a corrosão. Dos diferentes métodos conhecidos para proteção contra a corrosão, cada um tem suas vantagens e desvantagens na utilização. Na condição teórica, basicamente se trata de uma estrutura ser sacrificada para a conservação da outra, através de um circuito elétrico interligando as estruturas metálicas com cabos de energia entre si a uma placa de magnésio, criando assim um circuito onde a estrutura interligada a placa de magnésio $(\mathrm{Mg})$ passa a ter uma troca de elétrons pelo circuito proposto, sacrificando uma estrutura que é a placa de magnésio que possui um potencial de redução maior que o aço da estrutura metálica, preservando assim a estrutura metálica da corrosão.

Os experimentos foram realizados em parceria com a Universidade Presidente Antônio Carlos (UNIPAC) de Teófilo Otoni/MG que desenvolveu a parte experimental e a metalografia e Universidade Federal de Itajubá campus Itabira/MG (UNIFEI) onde foi feito o a difração de raio $\mathrm{x}$ (DRX).

Foi utilizado uma barra de aço de $1 / 2$ ", que posteriormente originou quatro amostras que foram submetidas em diferentes situações. Das quatro amostras, três foram envolvidas com uma fita do metal magnésio $(\mathrm{Mg}$ ) com diferentes dimensões, afim de criar uma área de proteção.

Os experimentos se iniciaram com a limpeza das quatro amostras de aço com tensoativo catiônico e material abrasivo a base de carbeto de silício e lã de aço. Posteriormente foram secadas em estufa com umidade em $20 \%$ e temperatura de $37^{\circ} \mathrm{C}$. Após o processo e limpeza e secagem, foi adicionado nas amostras o magnésio metálico na forma de fita, em diferentes dimensões com auxílio de um fio de aço galvanizado. Os materiais utilizados para a primeira experiência foram:

- Barra de "aço de $1 / 2$ " $=5$ pedaços de $21 \mathrm{~cm}$ de comprimento

- $\quad$ Fita de Magnésio $=76 \mathrm{~cm}$

- Fio de aço galvanizado

- Tensoativo catiônico

- Abrasivo (Carbeto de silício)

- Lã de aço 


\section{Res., Soc. Dev. 2019; 8(1):e181504 \\ ISSN 2525-3409 | DOI: http://dx.doi.org/10.33448/rsd-v8i1.504}

Após o preparo das amostras, as mesmas foram submetidas às condições que semelham as atmosféricas na qual as estruturas de aço ficam expostas, para em seguida realizar a caracterização de difração de raio $\mathrm{x}$ das amostras de ferro puro, ferro oxidado e ferro protegido com magnésio, seguido por metalografia afim de verificar a superfície do material.

\section{Resultados e Discussão}

Antes de iniciar as análises, foi realizado uma difração de raio x nas amostras das barras de aço, podendo comprovar que no início tínhamos apenas ferro, como ilustrado na Figura 3.

Figura 3: Difração de raio x da barra de aço antes da análise.

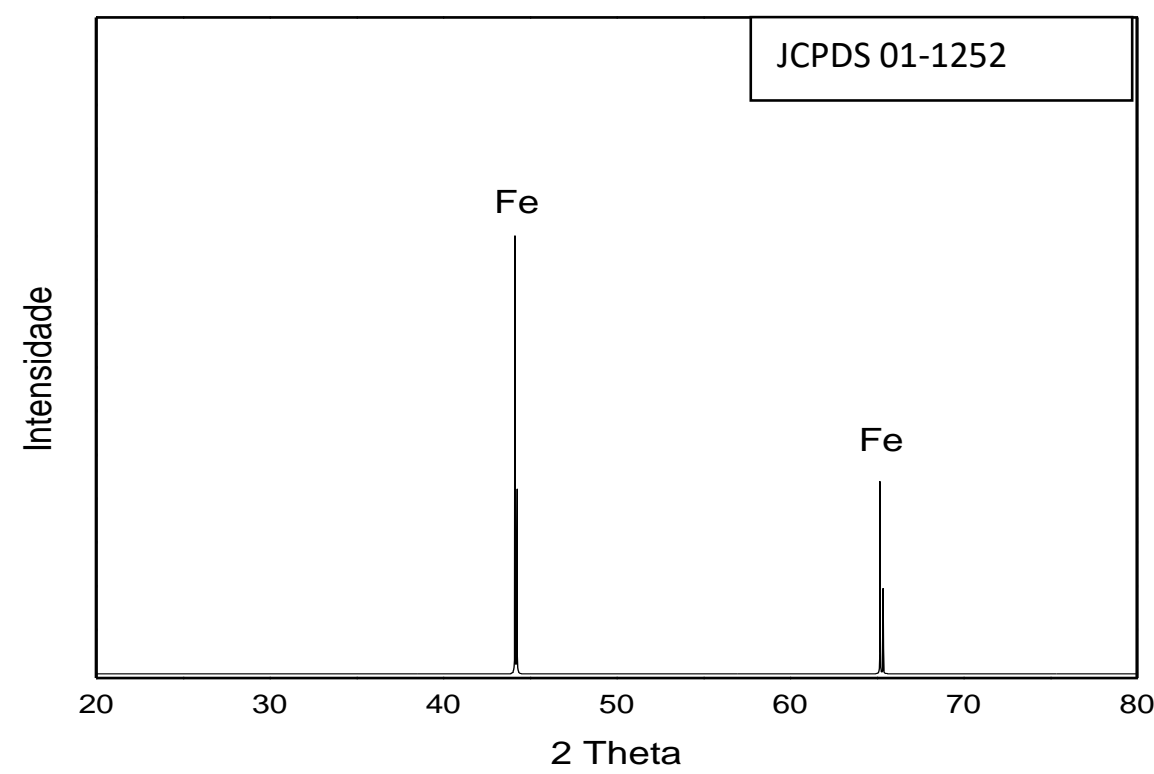

(Fonte: Autoria própria)

Com base em descrições de raio x, baseado em trabalhos publicados por SALOMÂA, P. E. A. (2017) na área de materiais, pode ser interpretado que a difração de raio $x$ picos característicos de ferro metálico na difração de raios-X, que se encontram em $44^{\circ}$ e $65^{\circ}$. Esses picos indicam a presença de grande parte de ferro, que no caso do perfil de ferro, se encontra na forma de uma liga metálica entre ferro e carbono de acordo com a ficha cristalográfica JCPDS 01-1252. 
O desenvolvimento do experimento se deu protegendo as amostras de perfil com uma fita do metal magnésio ( $\mathrm{Mg}$ ) como verificado na Figura 4, na qual em pouco tempo de exposição, os perfis de ferro começaram a oxidar.

Figura 4: Barras de aço com diferentes quantidades de magnésio (Mg) para o estudo da proteção.

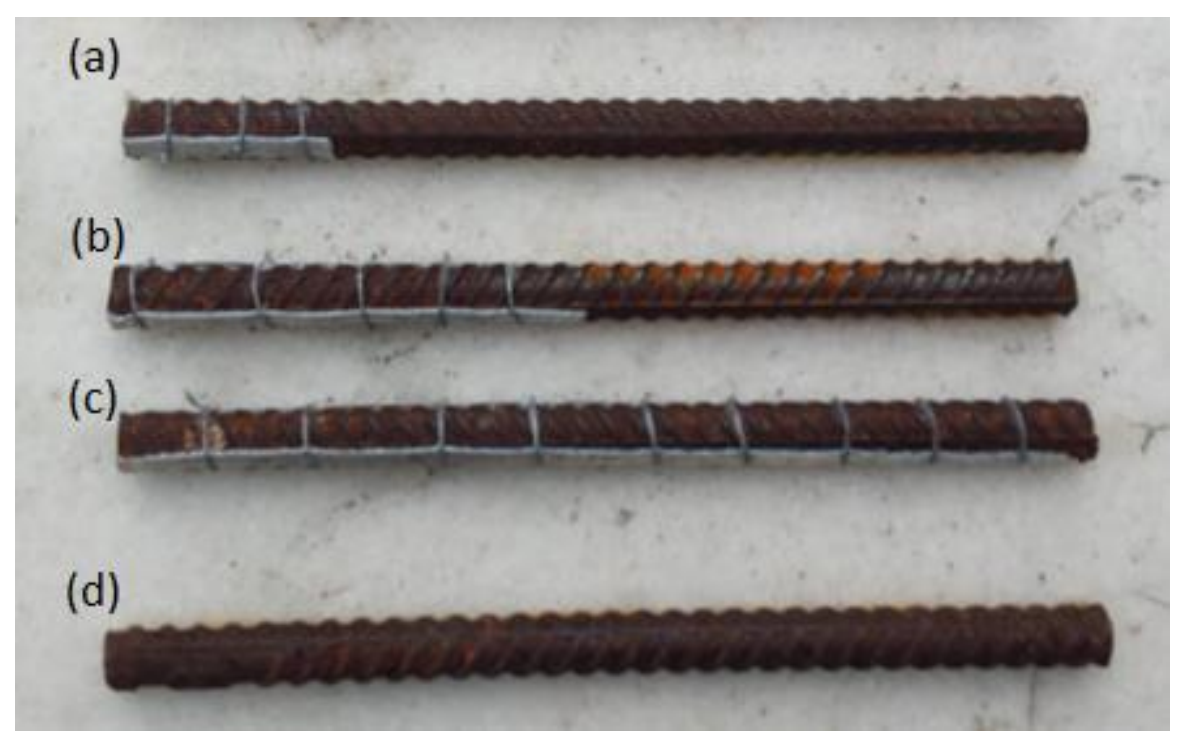

(Fonte: Autoria própria)

As barras de aço foram expostas aos agentes de intemperismo (sol, chuva, sereno, calor e frio) simulando condições na qual as mesmas ficam em canteiros de obras.

As exposições duraram em média 16 dias, tempo esse estimado em canteiro de obra local no município de Teófilo Otoni/MG. Tempo esse estimado desde a saída das barras de aço da distribuidora, chegada no canteiro de obras, manufatura das barras em esqueleto de vigas e posterior envolvimento por concreto.

Após os 16 dias, pode-se notar visualmente que as barras estavam oxidadas, como ilustrado na Figura 5 mostrada a seguir. 
Figura 5: $1^{\mathrm{a}}$ barra de aço a proteção foi feita com $3 \mathrm{~cm}$ de fita de magnésio.

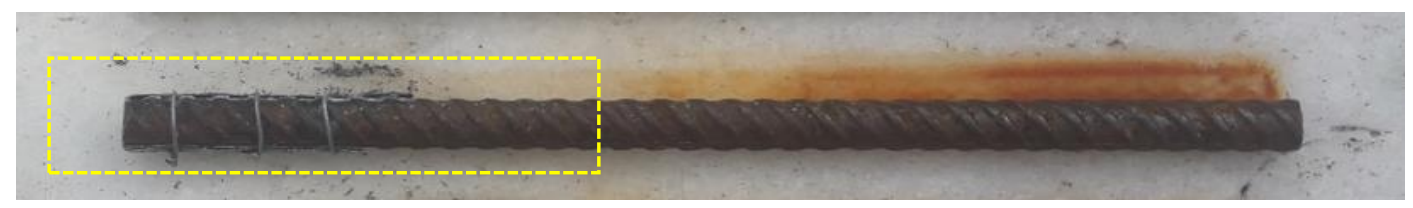

(Fonte: Autoria própria)

A primeira amostra da barra de aço, foi adicionado uma fita de magnésio de $3 \mathrm{~cm}$, na qual pode ser visto que a parte com a proteção não sofre com o processo de corrosão. $\mathrm{O}$ mesmo processo pode ser visto a seguir, na Figura 6 que teve uma área de proteção maior.

Figura 6: $2^{\mathrm{a}}$ barra de aço a proteção foi feita com $10 \mathrm{~cm}$ de fita de magnésio, a parte sem proteção foi aumentando a oxidação cada vez mais linde da fita.

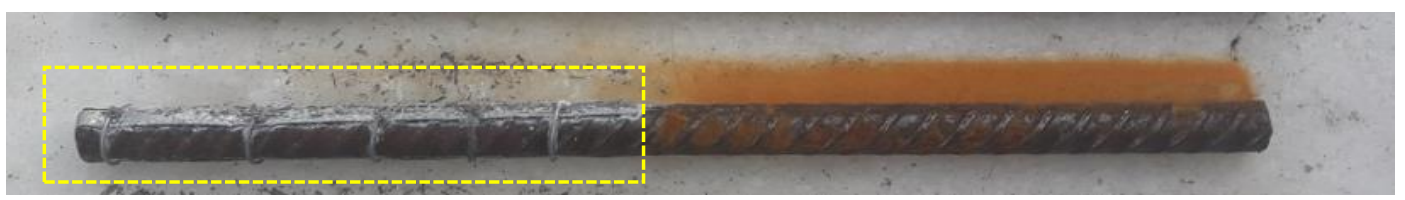

(Fonte: Autoria própria)

Na figura 6, foi utilizado um pedaço maior da fita de magnésio, na qual é visível que a proteção se manteve até a altura na qual foi feita a proteção com a fita de magnésio. A Figura 7 apresenta a barra de aço com uma camada de proteção maior.

Figura 7: $3^{a}$ barra de aço a proteção foi feita com $20 \mathrm{~cm}$ de fita o resultado comprova que a técnica funciona.

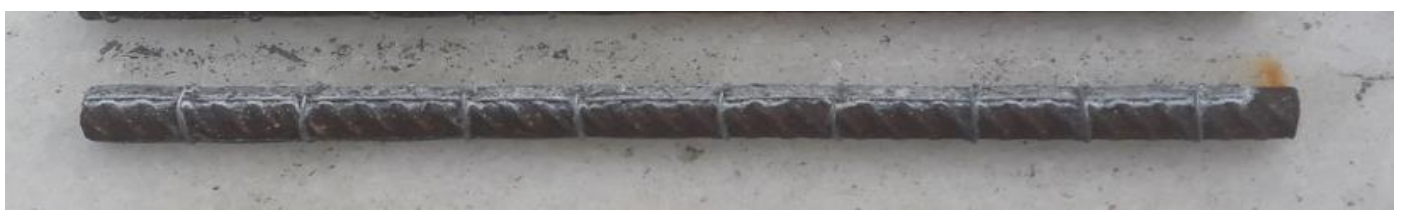

(Fonte: Autoria própria)

Na Figura 8, pode ser visto a barra amostral com quase toda sua totalidade protegida com a fita de magnésio, mostrando resultados satisfatórios contra a corrosão. Em 
continuidade, a Figura 8 apresenta a $4^{\mathrm{a}}$. Barra sem a proteção com o metal de sacrifício magnésio.

Figura 8: $4^{\mathrm{a}}$ Barra de aço sem proteção do metal magnésio.

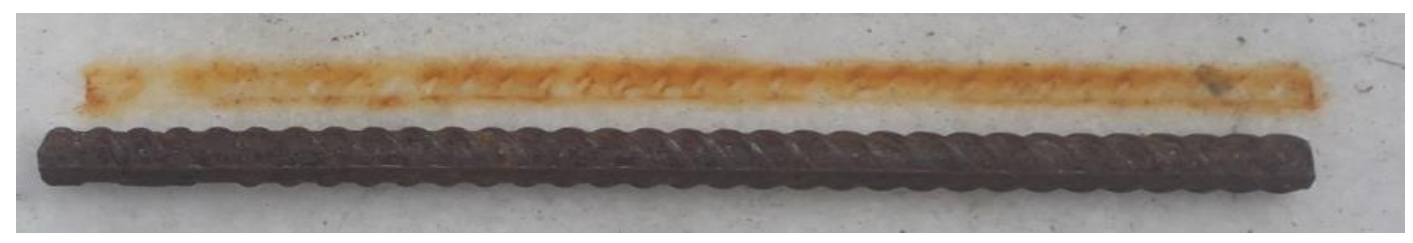

(Fonte: Autoria própria)

Na sequência das amostras, a $4^{\mathrm{a}}$ amostra, não teve adicionado em seu corpo o metal magnésio, ocasionando a oxidação por completo em toda o seu comprimento.

Afim de ilustrar melhor, na Figura 9 é feita a metalografia das amostras, na qual pode ser visto mais de perto os efeitos da proteção e da corrosão.

Figura 9: Metalografia da superfície da barra de aço, no local que não existia proteção com a fita de magnésio.

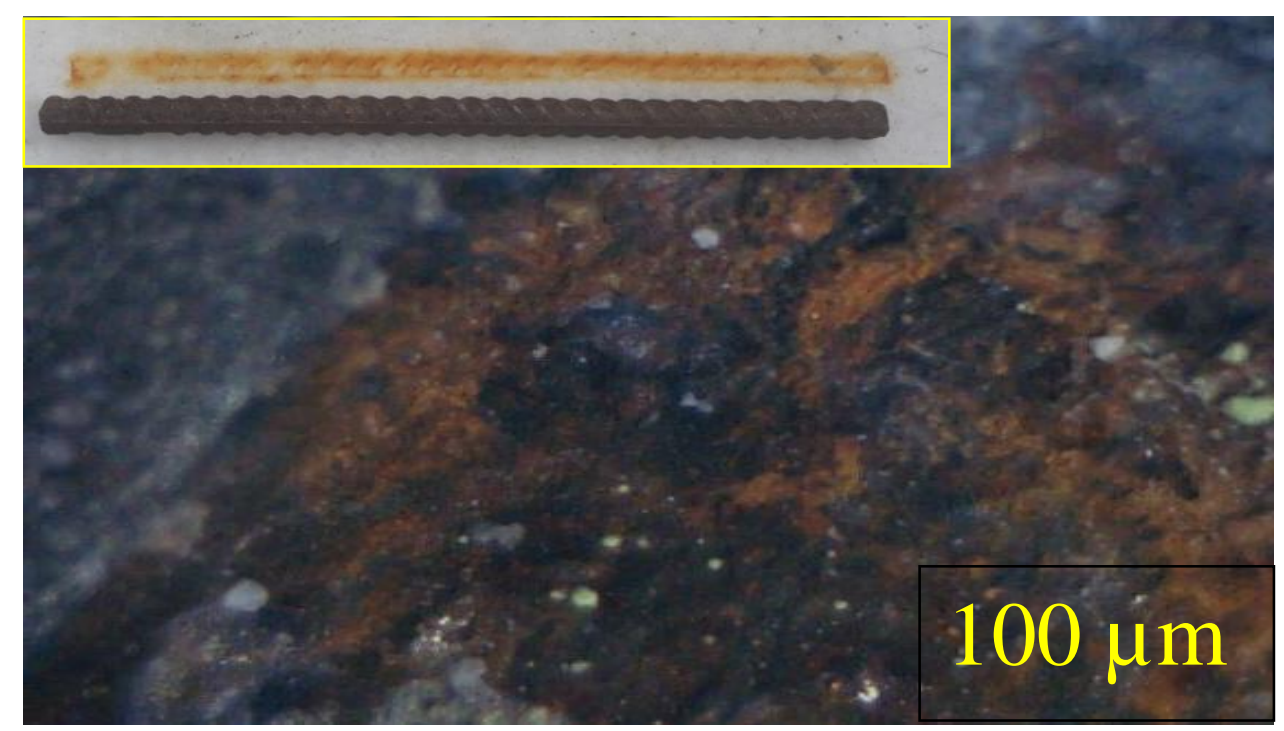

(Fonte: Autoria própria)

Visualmente pode ser visto que as amostras das barras de aço, sofreram oxidação em sua superfície, e essa oxidação se iniciou onde termina a proteção com a fita de magnésio. Por 
imagem metalográficas, como ilustrado na imagem 8, pode ser visto que existe uma camada mais alaranjada, indicando a presença de ferrugem $\left(\mathrm{Fe}_{2} \mathrm{O}_{3}\right)$.

Afim de confirmar a formação da ferrugem $\left(\mathrm{Fe}_{2} \mathrm{O}_{3}\right)$ foi realizada uma difração de raio x (DRX), da região ilustrada na metalografia, resultando na Figura 10.

Figura 10: Difração de raio x da superfície oxidada.

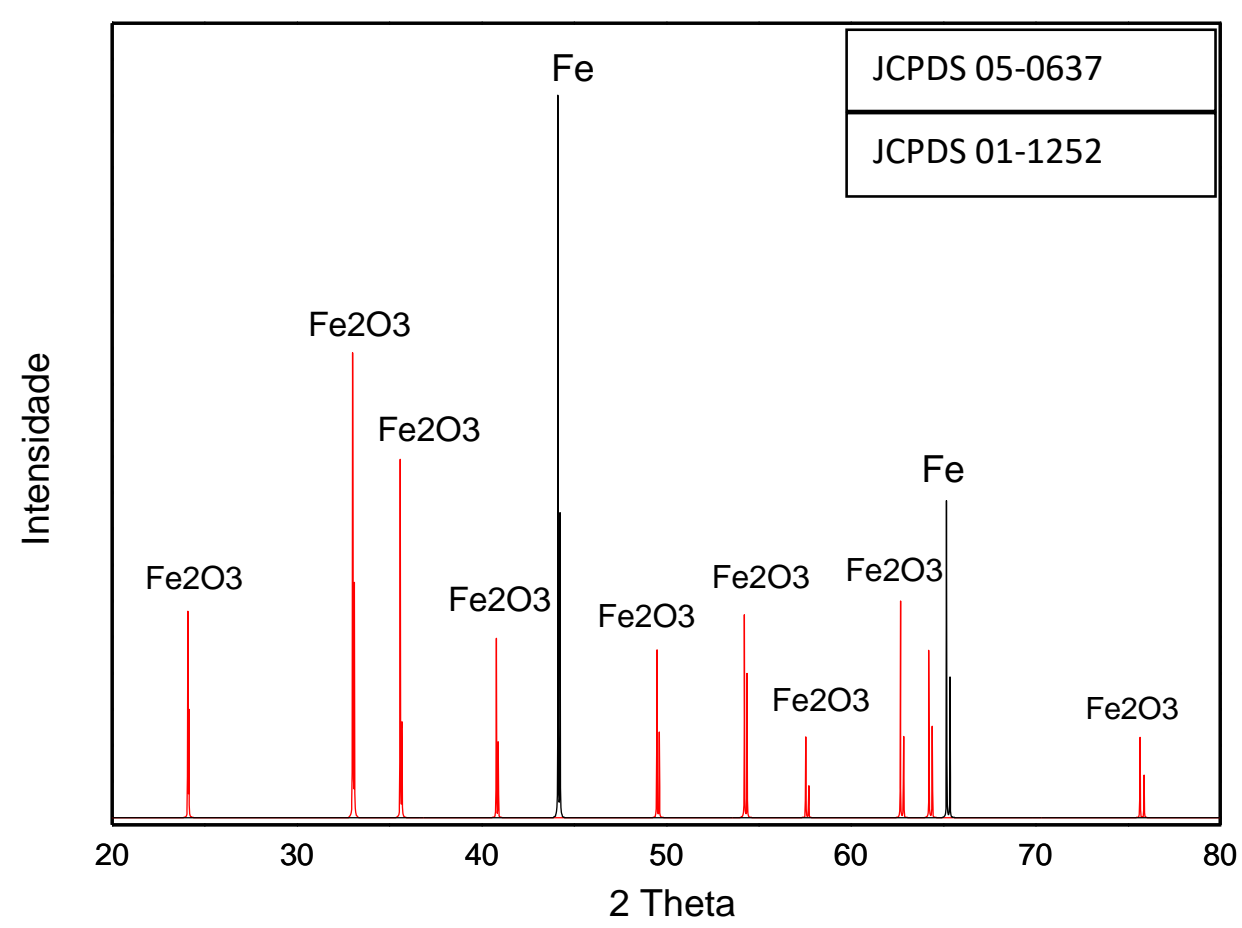

(Fonte: Autoria própria)

Pela difração de raio $\mathrm{x}$ da superfície oxidada, pode-se comprovar a presença de óxido de ferro (JCPDS 05-0637), que como ilustrado no gráfico estão presentes junto com o ferro (JCPDS 01-1252), presente inicialmente na barra de aço.

Ao mesmo tempo que a parte da barra de aço sem a fita de magnésio ficou exposta ao intemperismo, outra parte ficou em contato com a fita, evitando a formação da camada de óxido de ferro, como pode ser visto na imagem 9. 
Figura 11: Metalografia da parte da barra de aço que ficou em contato com a fita de magnésio.

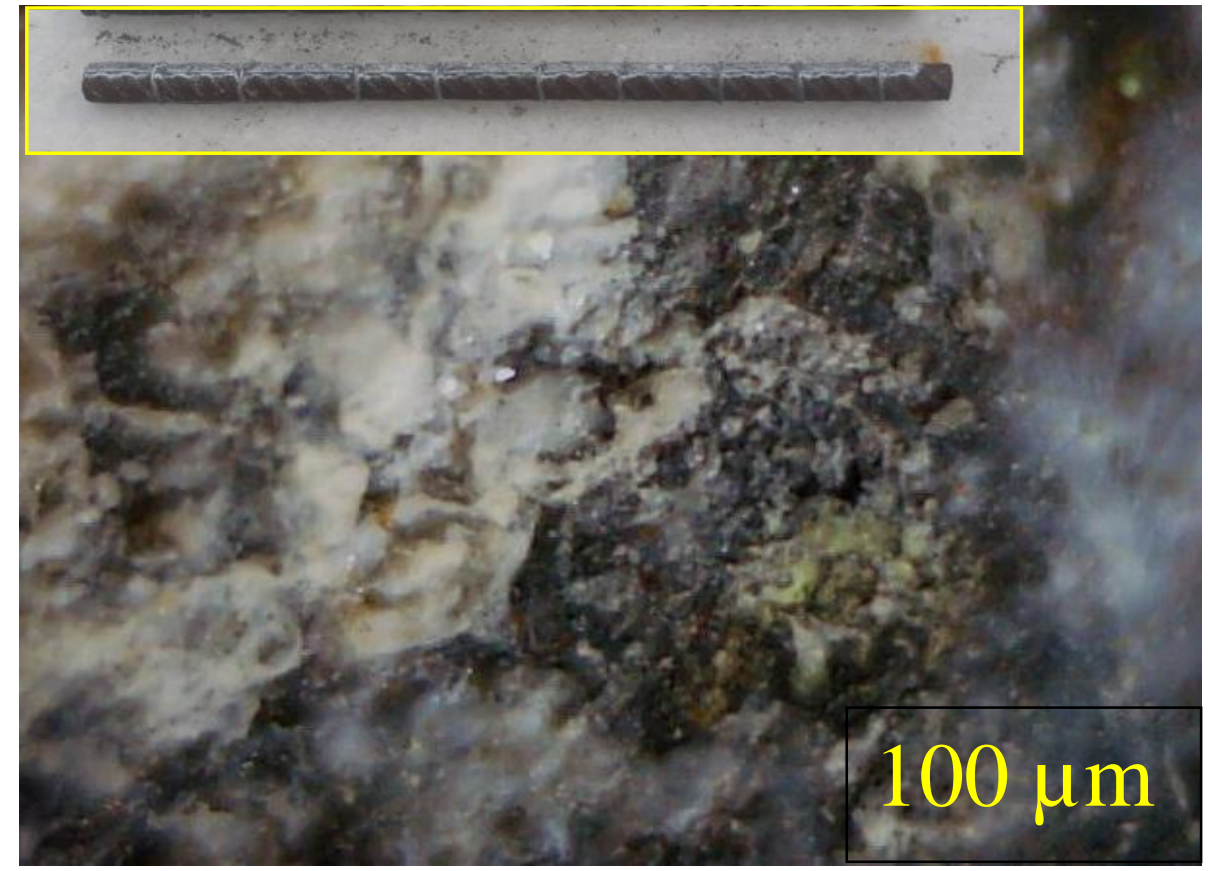

(Fonte: Autoria própria)

Superficialmente pode ser visto que a barra de aço não apresentou camada de coloração laranja, característica de ferrugem $\left(\mathrm{Fe}_{2} \mathrm{O}_{3}\right)$. Em proteção catódica de ligas metálicas, é utilizado um outro metal denominado de sacrifício. Na situação do experimento foi utilizado o magnésio (Mg), que por estar exposto as condições de intemperismo, sofreu uma oxidação, produzindo o óxido de magnésio, que acabou protegendo a barra de aço. Isso pode ser confirmado pela difração de raio x, ilustrado no gráfico 3. 
ISSN 2525-3409 | DOI: http://dx.doi.org/10.33448/rsd-v8i1.504

Figura 12: Difração de raio x da região de contato entre a fita de magnésio e a amostra.

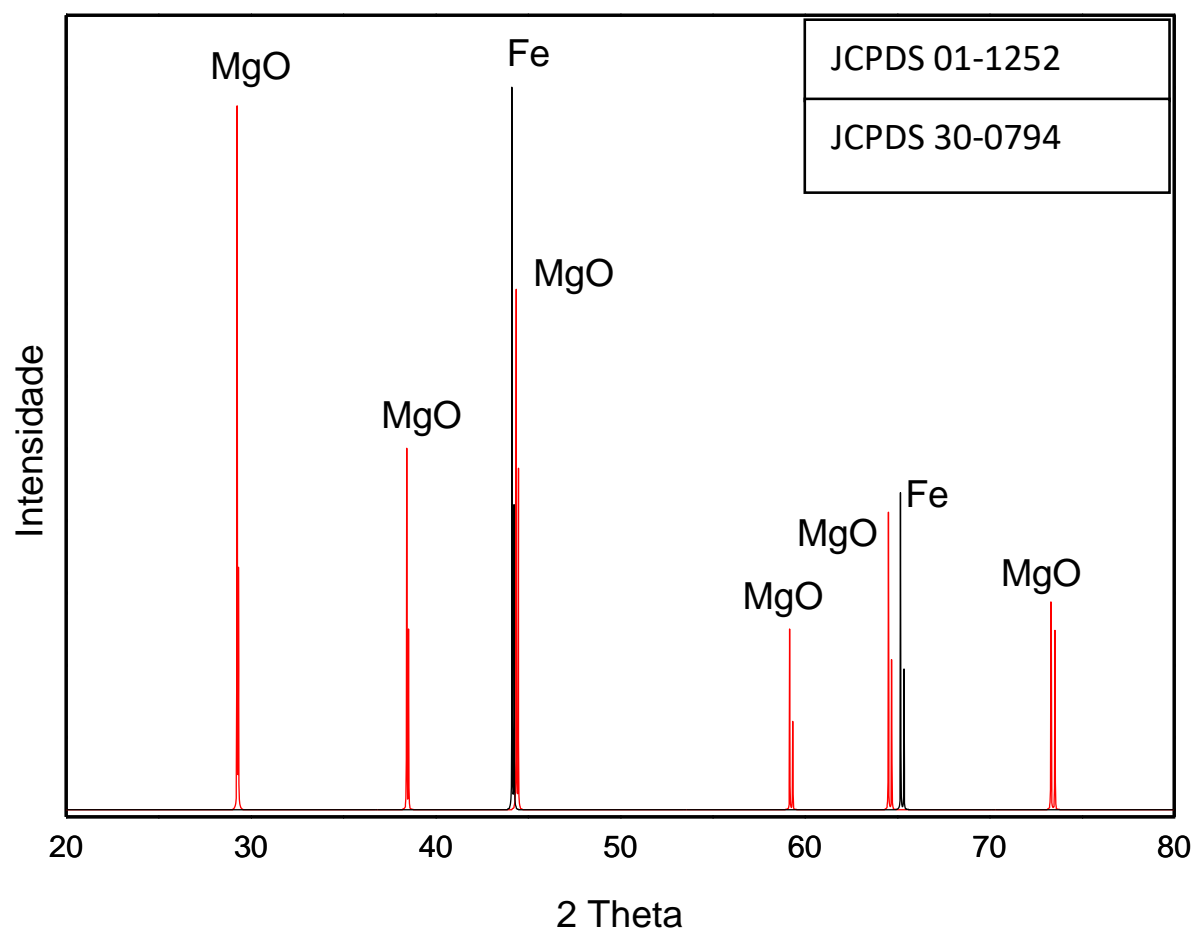

(Fonte: Autoria própria)

Como ilustrado na metalografia, superfície da barra de aço protegida com a fita de magnésio, não apresentou nenhuma camada de coloração laranja indicando a presença de óxido de ferro, como confirmado pela difração de raio x (JCPDS 01-1252), e ainda apresentou em sua superfície uma fina camada de óxido de magnésio, proveniente da oxidação do metal de sacrifício (JCPDS 30-0794) .

\section{Considerações finais}

O desenvolvimento do experimento foi motivado pelo controle de um problema comum na área de construção civil denominado corrosão do concreto, que gera perdas milionárias ao setor. 
Pode ser visto no desenvolvimento do artigo, que a proteção se faz necessário pois as barras de aço utilizadas na construção civil, não apresentam uma proteção tão eficiente, ficando expostos aos agentes do intemperismo.

A proteção da barra de aço com um metal de sacrifício se mostrou eficiente. Ao passo que na região sem a proteção houve a formação da camada de ferrugem, na região com a proteção não foi verificada a formação de ferrugem, indicando que a proteção de faz eficiente, no prazo médio na qual a barra de aço fica exposta no canteiro de obra.

Como descrito, esse artigo mostrou uma contribuição científica na qual pode ser feito a proteção de estruturas metálicas com metal de sacrifício, afim de evitar gastos e aumentar a vida útil das ferragens da construção civil.

Como sugestão de trabalhos futuros, podem ser feitos estudos e testes de resistência da estrutura metálica com a proteção de magnésio e acompanhamento de uma obra de construção civil com esse tipo de proteção.

\section{Referências}

ALVES, Elcio Cassimiro. Projeto ótimo de Pilares em Concreto de Alta Resistência Segundo ABNT NBR 6118: 2014. Revista Sul-americana de Engenharia Estrutural, v. 15, n. 1, 2018.

ANGST, Ueli M. Challenges and opportunities in corrosion of steel in concrete. Materials and Structures, v. 51, n. 1, p. 4, 2018.

BOKATI, Kazem Sabet; DEHGHANIAN, Changiz; YARI, Saeed. Corrosion inhibition of copper, mild steel and galvanically coupled copper-mild steel in artificial sea water in presence of $1 \mathrm{H}$-benzotriazole, sodium molybdate and sodium phosphate. Corrosion Science, v. 126, p. 272-285, 2017.

BROOMFIELD, John P. Corrosion of steel in concrete: understanding, investigation and repair. CRC Press, 2003.

GONZALEZ, J. A. et al. Comparison of rates of general corrosion and maximum pitting penetration on concrete embedded steel reinforcement. Cement and concrete research, v. 25, n. 2, p. 257-264, 1995. 
Res., Soc. Dev. 2019; 8(1):e181504

ISSN 2525-3409 | DOI: http://dx.doi.org/10.33448/rsd-v8i1.504

HA, Jung Hoon et al. 1-Butyl-1-methylpyrrolidinium chloride as an effective corrosion inhibitor for stainless steel current collectors in magnesium chloride complex electrolytes. Journal of Power Sources, v. 355, p. 90-97, 2017.

MCCULLOUGH, Colin et al. Environmental Field Trial of an Overhead Power Transmission Conductor in a High Corrosion Rate Coastal Atmosphere in Peru. In: CORROSION 2017. NACE International, 2017.

SALOMÃO, Pedro Emílio Amador et al. Elaboration of tables for concrete dosage based on the aggregates used in Northeast Mineiro. Research, Society and Development, v. 7, n. 4, p. $1274305,2018$.

SALOMÃO, Pedro Emílio Amador. Influência da cristalinidade no band gap de cerâmicas avançadas a base de titanatos. Revista Eletrônica de Materiais e Processos, v. 12, n. 3, 2017.

SINEX, Scott A.; HALPERN, Joshua B.; JOHNSON, Scott D. General Chemistry for Engineers in the 21st Century: A Materials Science Approach. MRS Advances, v. 2, n. 31 32, p. 1629-1634, 2017.

SUGISAWA, Haruki et al. Corrosion resistance and mechanical properties of titanium nitride plating on orthodontic wires. Dental materials journal, v. 37, n. 2, p. 286-292, 2018.

SVORONOS, Paris. From Introductory Chemistry at the Community College Level to PostUndergraduate Success: Strategies at Queensborough Community College that Secure the Success of Ethnically Diverse STEM Students. In: Diversity in the Scientific Community Volume 2: Perspectives and Exemplary Programs. American Chemical Society, 2017. p. 95-114.

TUUTTI, Kyösti. Corrosion of steel in concrete. 1982.

ZHU, Wenjun et al. Influences of corrosion degree and corrosion morphology on the ductility of steel reinforcement. Construction and Building Materials, v. 148, p. 297-306, 2017. 